\title{
Secondary tonsillar hemorrhage requiring surgical intervention: Analysis of 1429 tonsillectomy cases on single surgeon experience
}

\author{
Seyit Mehmet Ceylan ${ }^{1 *}$, Erdal Uysal ${ }^{2}$, Ilyas Disikirik ${ }^{1}$
}

\begin{abstract}
Objective: Determination of risk factors affecting secondary tonsillar hemorrhage of the requiring surgical intervention.
\end{abstract}

Material and methods: The 1429 tonsillectomy cases were performed with three different dissection techniques (dissection and snare, bipolar and monopolar dissection) by a single surgeon were examined retrospectively. Age, sex, surgical knowledge, indications and postoperative tonsillar hemorrhage day of the patients were recorded. Patients who were operated on for hemorrhage were evaluated statistically in terms of technique used, age, sex and indications.

Results: A total of 25 cases of a secondary hemorrhage cases requiring surgical intervention were detected. The relationship between age and bleeding was statistically significant $(p=0.003)$. Hemorrhage frequency requiring surgical intervention was significantly higher in patients with recurrent tonsillitis than in patients with tonsillar hypertrophy $(\mathrm{p}=0.001) .19$ of the 25 patients who were operated on for hemorrhage were in the group of tonsillectomy patients due to recurrent tonsillitis. There was no meaningful relationship in terms of sex. The hemorrhage rate in the dissection and snare technique was 1.74\% (12 patients), the hemorrhage rate in bipolar dissection was $2.78 \%$ (9 patients), and the monopolar dissection- hemorrhage rate was $0.96 \%$ (4 patients). There was no statistically significant difference between the results $(p=0.170)$. It was determined that the hemorrhage required surgery at most was between 6 th and 10 th days.

Conclusion: While there was no significant relationship between the incidence of secondary tonsillar hemorrhage requiring surgery and gender and dissection techniques, it has been observed that the risk was increased in patients operated due to recurrent tonsillitis and older age group.

Key words: Tonsillectomy, Hemorrhage, Risk factors

\section{Introduction}

Tonsillectomy is one of the oldest and most commonly performed otolaryngologic procedures (1). A post-tonsillectomy hemorrhage rate, which is one of the complications of this procedure, varies from $2.1 \%$ to $12 \%$ when all age groups are taken into consideration (2-4). In general, the rate of second surgical procedure due to tonsillar hemorrhage is between $1.2 \%$ and $6 \% \quad(3,4)$. Post-tonsillectomy hemorrhages are classified as primary (within $24 \mathrm{~h}$ postoperatively) and secondary (after $24 \mathrm{~h}$ postoperatively) (5). It is known that primary hemorrhage depends on inadequate bleeding control during surgery. Secondary hemorrhage occurs due to the detachment of the crusts in the tonsillar fossa (6).

Currently described tonsillectomy techniques are cold dissection, bipolar and monopolar dissection, bipolar scissor dissection, laser, cryosurgery, ultrasonic excision, microdebrider, coblation, thermal welding and plasma knife methods $(7,8)$. These methods have been developed to achieve less intraoperative hemorrhage, less surgical time, and less postoperative pain (8)

Previously reported risk factors in tonsillar hemorrhage include age, gender, indications, surgical techniques and instruments used, and the surgeon's experience (9-14). Electro-surgery in some publications has been described as a risk factor for postoperative hemorrhage or secondary tonsillar hemorrhage (15-17). In addition, a significant association between primary tonsillar haemorrhages that occur in the first 4 hours postoperatively, and cold dissection has been reported (18). Cold technical tonsillectomy has more hemorrhage intraoperatively; however, postoperative pain is less than electrosurgical methods (6).

Received 09-06-2017 Accepted 17-06-2017 Available Online 30-06-2017

1 Sanko Hospital, Dept. of Otolaryngology, Gaziantep, TR

2 Sanko University, School of Medicine, Dept. of General Surgery, Gaziantep, TR

* Corresponding Author: Seyit Mehmet Ceylan E-mail: drmehmetceylan@hotmail.com Phone: +90 3422116500 
This study was designed to determine the risk factors affecting the secondary tonsil hemorrhage requiring surgical intervention through the experience of a single surgeon.

\section{Material and Methods}

The 1429 tonsillectomy operation performed by a single surgeon between 2010-2017 was included in the study. Patients who underwent only tonsillectomy and also adenoidectomy were included in the study. Tonsillectomies performed as part of the uvulopalatopharyngoplasty, tonsillectomies with malignancies suspected patients, tonsillectomies performed with nasal operations, and those with insufficient knowledge of the records were excluded from the study. The medical records were examined retrospectively in the electronic records. Age, sex, and indications were noted on the day of the patients who underwent hemorrhage control under general anaesthesia because of the most objective hemorrhage from patient data.

Indications for tonsillectomy disease were determined due to recurrent tonsillitis ( $\geqslant 7$ over one year, $\geqslant 5$ over two years, $\geqslant 3$ over three years) and/or tonsil hypertrophy resulting in snoring or respiratory disturbance in sleep. Informed consent form was obtained from each patient or parent. All tonsillectomies were performed under general anaesthesia. Patients were discharged after approximately 6-8 hours of follow-up on the operation day. The patient was given a brochure containing the patient's tonsil diet and the surgeon's phone number without exception to call in case of hemorrhage. Each patient was prescribed 2nd generation cephalosporin and metamizole as a pain reliever. In case of allergy, macrolide group antibiotic and ibuprofen as an alternative for metamizole were prescribed. Additional diclofenac in intramuscular form was recommended for adult patients.

The surgeon used the dissection and snare technique in tonsillectomy performed between 2010 and 2013 . After this date, the surgeon started using dissection with bipolar cautery. After using this technique till 2015 , the surgeon was used dissection with monopolar cautery and still uses this technique.

A mucosa incision was performed in the anterior, superior and posterior tonsillitis in a dissection and snare technique using a tonsil knife. The upper pole of the tonsil was held with an Allis forceps and the extracapsular plan was inserted with the help of scissors and elevator to provide a dissection. Inferior pole was excised with the help of snare. It was waited for 7 minutes by performing tamp. Subsequent bleeds were stopped by cauterizing with bipolar cautery. Bonding and suturing were rarely used in hemorrhage from large diameter vessels. Extracapsular dissection was performed only in bipolar dissection using Allis forceps and bipolar cautery.
The monopolar dissection was performed in the same manner using Allis forceps and monopolar cautery alone. Bipolar dissection and monopolar dissection and hemorrhage control were performed in 20 -watt power mode electrocautery.

\section{Statistical analyses}

SPSS 22.0 (IBM Corporation, Armonk, New York, United States) program was used to analyse the variables. The normal distribution of the data was evaluated by the Shapiro-Wilk test and variance homogeneity of the date was assessed by the Levene test. Independent-Samples T test along with Bootstrap results was used when comparing two independent groups according to quantitative data. Pearson ChiSquare and Fisher Exact tests were used to compare categorical variables. Exact results were tested with the Monte Carlo Simulation technique. Quantitative variables and categorical variables were shown as mean \pm SD (standard deviation) and as $\mathrm{n}(\%)$, respectively, in Tables. Variables were examined at $95 \%$ confidence level and $\mathrm{p}<0.05$ was accepted as significant.

\section{Results}

Due to the analysis of demographic data of patients, there was no statistically significant difference in terms of age, sex, and indications between the patient groups in which three different dissection techniques were applied. The distribution of the patients and the demographic data are shown in Table 1.

There was no statistically significant relationship between hemorrhage and sex $(p=0.316)$. When the association between hemorrhage and age was examined, there was a statistically significant relationship between age and hemorrhage risk ( $p=$ 0.003). While the general average of the patient population was 7.57 , the mean ages of the patients, who were operated on for hemorrhage, was 14.32. The hemorrhage was found to be statistically significantly higher in patients operated for recurrent tonsillitis $(\mathrm{p}=$ $0.001)$. In total, 19 of 25 patients who were operated on due to hemorrhage were patients who underwent tonsillectomy because of recurrent tonsillitis.

When the dissection methods used were compared with each other, the highest hemorrhage rate in percentage was bipolar dissection with $2.78 \%$. This rate was $1.75 \%$ in the dissection and snare method and $0.96 \%$ in the monopolar dissection. There was no statistically difference between these three methods ( $p$ $=0.170)$.

When the day of the hemorrhage was observed, the secondary hemorrhage was seen between the 4th and 13th day. Most of the haemorrhages were between the 6 th and 10th days. It was seen that 19 out of 25 bleedings were on within these day (Figure 2). 
A

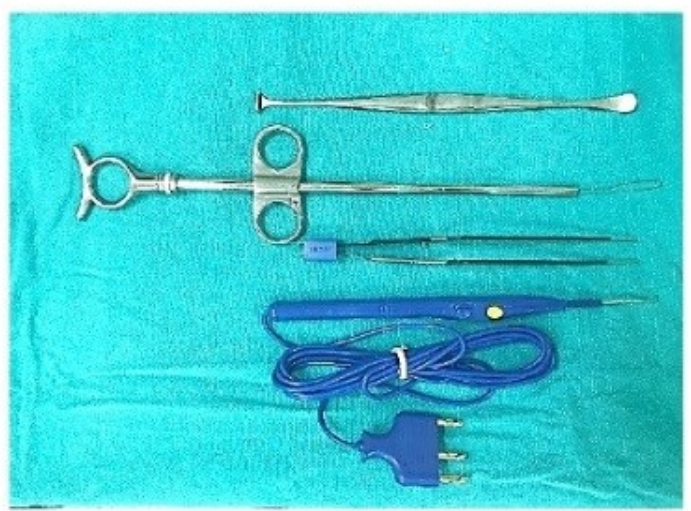

C

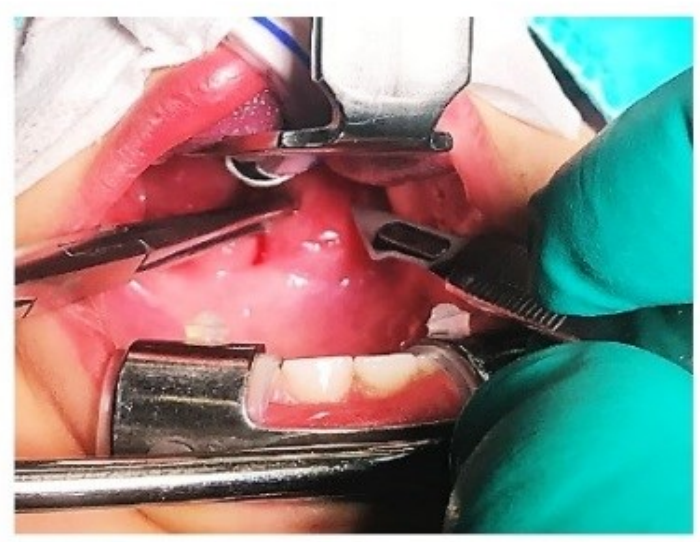

E

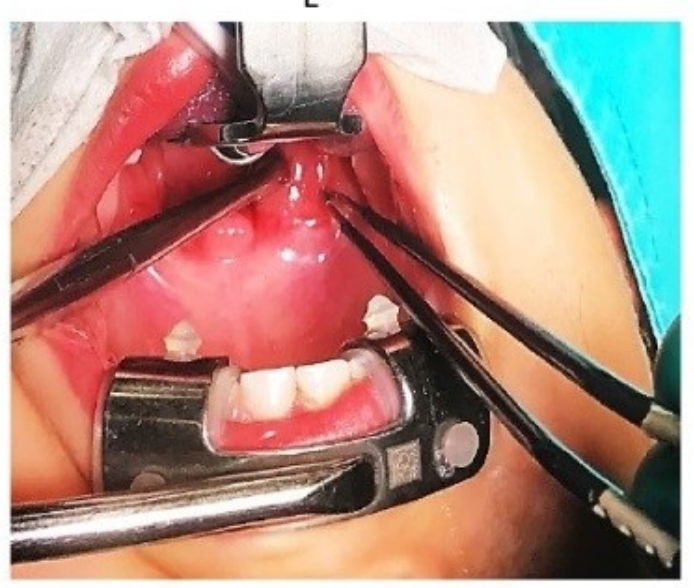

B

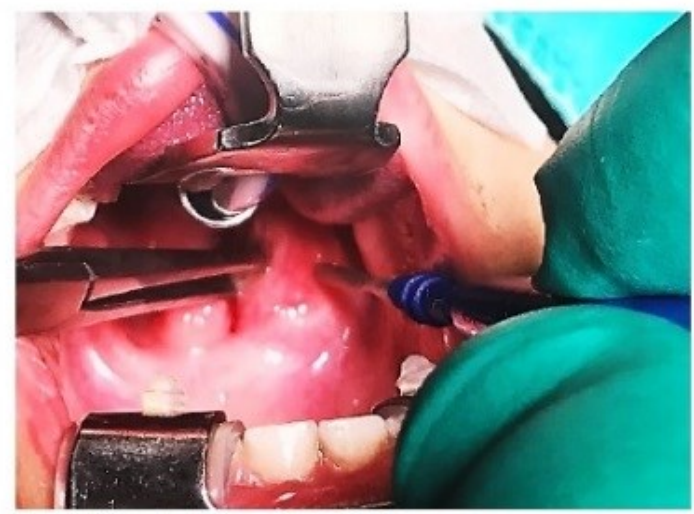

D

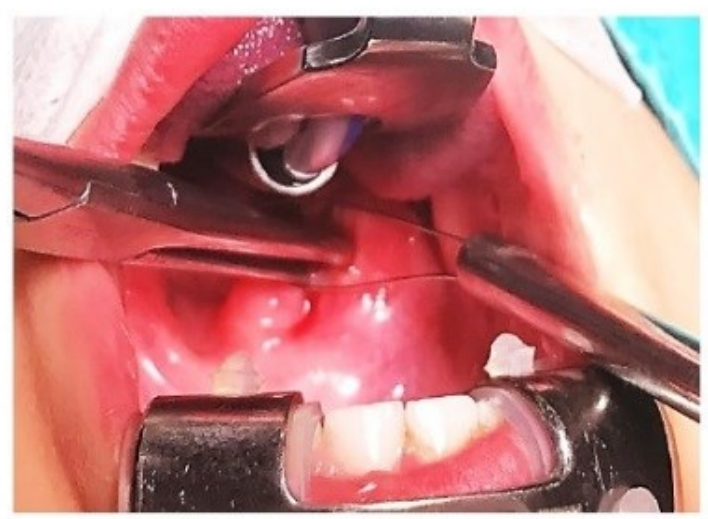

F

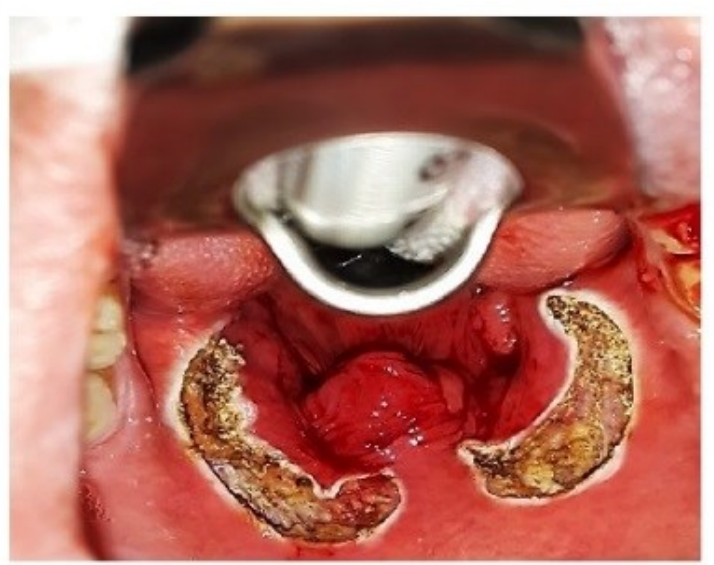

Figure 1: Intraoperative appearance of dissection methods. A: instruments of dissection, B: Monopolar dissection technique, C, D: dissection and snare technique, E: Bipolar dissection, F: Appearance of tonsil bed after haemostasis 
Table 1: Demographic characteristics of patients

\begin{tabular}{|c|c|c|c|c|c|}
\hline & $\begin{array}{l}\text { Dissection } \\
\text { and snare }\end{array}$ & $\begin{array}{c}\text { Bipolar } \\
\text { dissection }\end{array}$ & $\begin{array}{c}\text { Monopolar } \\
\text { dissection }\end{array}$ & Total & \multirow[t]{2}{*}{$\begin{array}{c}\mathbf{P} \\
\text { value }\end{array}$} \\
\hline & $(n=689)$ & $(n=324)$ & $(n=416)$ & $(\mathrm{N}=1429)$ & \\
\hline & $n(\%)$ & $n(\%)$ & $n(\%)$ & $\mathbf{N}(\%)$ & \\
\hline \multicolumn{6}{|l|}{ Gender } \\
\hline Female & $378(54,86)$ & $174(53,70)$ & $227(54,57)$ & $779(54,51)$ & 0,943 \\
\hline Male & $311(45,14)$ & $150(46,30)$ & $189(45,43)$ & $650(45,49)$ & \\
\hline \multicolumn{6}{|l|}{ Indications } \\
\hline Recurrent tonsillitis & $265(38,46)$ & $116(35,80)$ & $162(38,94)$ & $543(38)$ & 0,756 \\
\hline Tonsil hypertrophy & $366(53,12)$ & $181(55,86)$ & $226(54,33)$ & $773(54,09)$ & \\
\hline Both & $58(8,42)$ & $27(8,33)$ & $28(6,73)$ & $113(7,91)$ & \\
\hline \multicolumn{6}{|l|}{ Hemorrhage } \\
\hline Occurred & $677(98,26)$ & $315(97,22)$ & $412(99,04)$ & $1.404(98,25)$ & 0,170 \\
\hline Not occur & $12(1,74)$ & $9(2,78)$ & $4(0,96)$ & $25(1,75)$ & \\
\hline
\end{tabular}

Pearson Chi-Square Test(Monte Carlo)

Table 2: Clinical-demographic characteristics of patients presenting with secondary hemorrhage requiring surgical intervention

\begin{tabular}{|c|c|c|c|c|}
\hline & $\begin{array}{c}\text { No bleeding } \\
(n=1404)\end{array}$ & $\begin{array}{c}\text { Bleeding } \\
(n=25)\end{array}$ & $\begin{array}{c}\text { Total } \\
(\mathrm{N}=1429)\end{array}$ & P Value \\
\hline & Mean \pm SD & Mean \pm SD & Mean \pm SD & \\
\hline Age & $\begin{array}{c}7,45 \pm 5,33 \\
\mathbf{n}(\%)\end{array}$ & $\begin{array}{c}14,32 \pm 6,77 \\
\mathbf{n}(\%)\end{array}$ & $\begin{array}{c}7,57 \pm 5,43 \\
\mathbf{n}(\%)\end{array}$ & $\mathbf{0 , 0 0 3}$ \\
\hline \multicolumn{5}{|l|}{ Gender } \\
\hline Female & $768(54,70)$ & $11(44)$ & $779(54,51)$ & 0,316 \\
\hline Male & $636(45,30)$ & $14(56)$ & $650(45,49)$ & \\
\hline \multicolumn{5}{|l|}{ Indications } \\
\hline Recurrent tonsillitis & $524(37,32)$ & $19(76)$ & $543(38)$ & 0,001 \\
\hline Tonsil hypertrophy & $767(54,63)$ & $6(24)$ & $773(54,09)$ & \\
\hline Both & $113(8,05)$ & $0(0)$ & $113(7,91)$ & \\
\hline
\end{tabular}

Independent T Test(Bootstrap) - Pearson Chi-Square Test (Exact) - Fisher Exact Test(Monte Carlo) SS.:Standart deviation

Fig. 2. Periods of hemorrhage

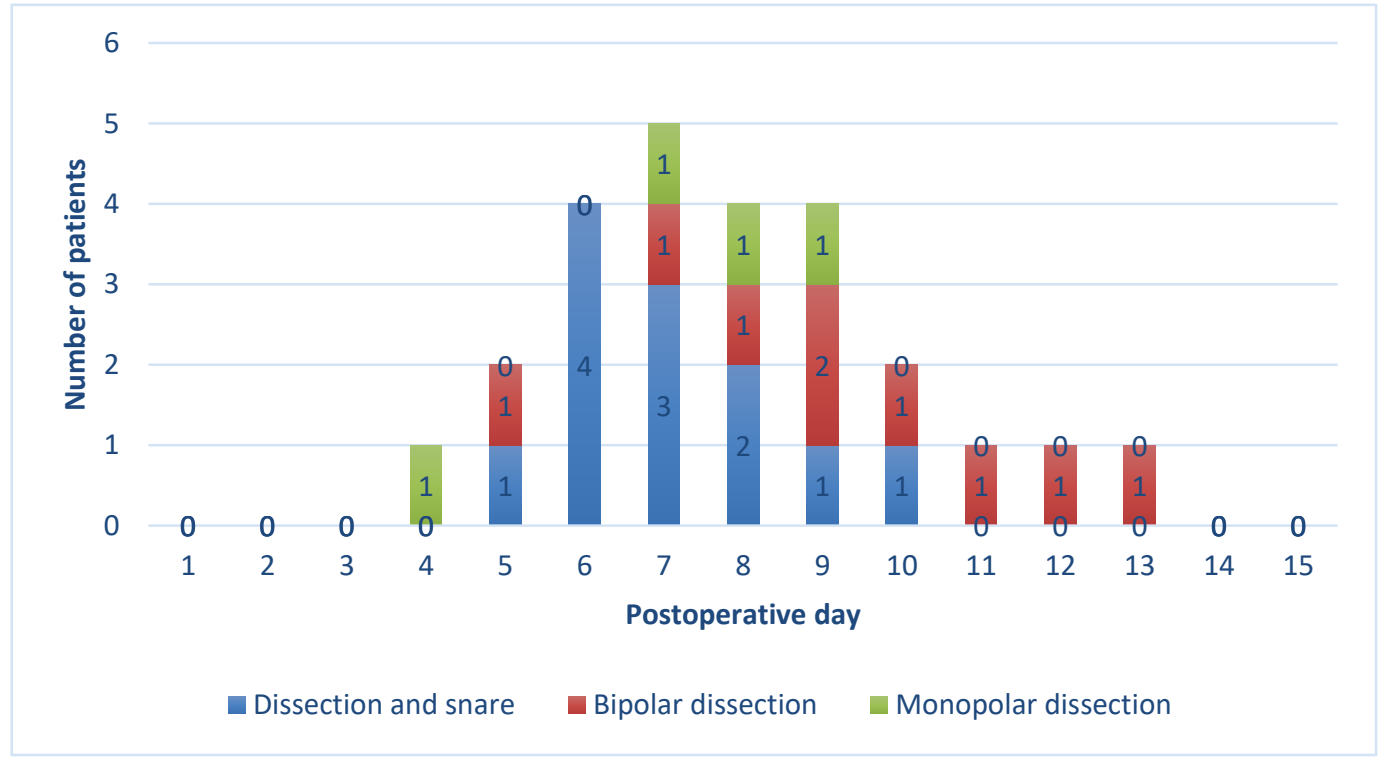




\section{Discussion}

Electrocautery dissection is preferred because it causes less intraoperative hemorrhage and shortens the operation time. However, studies in which hot instrumentation increases postoperative bleeding are included in the literature (15-17). The records of primary and non-surgical hemorrhage were not evaluated because they were inadequate in our data, but the hemorrhage rates required for surgical intervention were similar to the rates of hemorrhage for cold dissection in the literature. When evaluating the results of these three different tonsillectomy techniques using hot instrumentation, it cannot be said that the hot instrumentation has increased the hemorrhage rate. In all patients included in the study, the rate of second surgery for secondary hemorrhage was $1.7 \%$, which was consistent with rates of $1.2 \%$ and $6 \%$ in the literature $(3,4)$. When we compared the dissection and snare method with bipolar dissection, although the percentage of second hemorrhage required in the bipolar dissection is not statistically significant, it can be explained by the more intensive use of the hot instrument in bipolar technique. In fact, it is stated in the literature that the use of hot instrumentation increases the hemorrhage and the use of bipolar technique to only control hemorrhage has moderate risk $(17,19)$. On the other hand, secondary hemorrhage requiring a second surgery has a decline in percentage in monopolar dissection. Although the results show that monopolar cortical dissection has the best rate in terms of secondary hemorrhage requiring surgery, the data on which technique is better seems inadequate in the literature (20). Furthermore, there was no statistically significant difference in terms of the rate of secondary hemorrhage requiring surgery among the three techniques used. The choice of instrumentation is determined by the surgeon and the facilities owned. On the other hand, it is argued that every surgeon must learn and apply cold dissection before learning other methods (21).

Some publications have found hemorrhage rates associated with age $(9,12,17,22,23)$, but others have not established such a relationship $(24,25)$. There is a publication in the literature, which indicates that the age of the seconder hemorrhage under 6 years of age is less than all other age groups and hemorrhage rates in adults and adolescents are 5 times higher (26). Tomkinson and colleagues reported a 3 -fold increase in the proportion of severe hemorrhage in patients over 12 years of age in 17,480 tonsillectomy cases (12). In this retrospective study, there were no patients under 6 years of age in the patients who were operated for secondary hemorrhage and the patients were predominantly 12 year old and older. When the patient ages are considered, the results showed that the risk of hemorrhage is significantly higher at 12 years of age and over.
The current literature suggests that post-tonsillectomy hemorrhage risk in patients who have been selected for recurrent and chronic tonsillitis is higher than that for patients with tonsil hypertrophy (27). The data in this study also supports this statement.

Male gender is regarded as a risk factor for bleeding after tonsillectomy by various authors $(9,12,17,22)$. However, there was no significant relationship between gender and hemorrhage risk in this study.

Seconder tonsil haemorrhages tend to occur in the first week after surgery $(5,28)$ and rarely require surgery after the first 10 days $(29,30)$. When the patient data in the study were examined, it was observed that the hemorrhage occurred mainly between postoperative 6th and 10th days and there was no hemorrhage requiring surgery after the 13 th day of surgery. The most common hemorrhage was on the 7 th day.

This retrospectively designed study does not provide information on primary and non-surgical haemorrhages. Another weakness of the study is the use of hot instrumentation in hemorrhage control in all three methods. On the other hand, it was observed in this study that the method of dissection did not significantly change the hemorrhage rates.

In summary, if the factors related to the surgeon affecting bleeding rate are taking into consideration $(11,12,31)$, in this article which compares three different dissection methods based on single surgeon experience, while it was shown that age, recurrent tonsillitis and used instrumentation affect secondary bleeding rates, it has been observed that in monopolar cautery dissection the percentage required for surgery is reduced in the number of hemorrhage compared to dissection and snare technique and bipolar dissection. However, the differences are not statistically significant.

This study allowed us to evaluate the effect of different surgical techniques on the frequency of secondary hemorrhage regardless of surgeon experience. In addition, it provided the opportunity to evaluate the risk factors mentioned in the literature in a wide range series of tonsillectomy performed by a single surgeon.

\section{Conclusion}

Bleeding from time to time as a post-tonsillectomy complication can be life threatening. It can be very annoying for the surgeon when the family and the patient are in serious anxiety. In this study, which was based on single surgeon experience, an increase was determined in patients operated due to recurrent tonsillitis and in the frequency of secondary tonsil hemorrhage requiring surgical intervention in older age groups. On the other hand, it was observed that gender and methods used in dissection did not affect the hemorrhage risk. 
Conflict of Interest: The authors declare no potential conflicts of interest with respect to the research, authorship, and/or publication of this article.

Author's Contributions: SMC, EU, ID: Collecting of patients data, Patient examination and operation, writing and revision of article, HC: Statistical analysis of findings.

Ethical issues: All Authors declare that Originality of research/article etc... and ethical approval of research, and responsibilities of research against local ethics commission are under the Authors responsibilities. The study was conducted due to defined rules by the Local Ethics Commission guidelines and audits.

Acknowledgements: The authors would like to thank Dr. Hüseyin Candan for the statistical analysis

\section{References}

1. Baugh RF, Archer SM, Mitchell RB, et al., Clinica practice guideline: tonsillectomy in children, Otolaryngol Otolaryngol Head Neck Surg. 2011;144(1):1-30.

2. Bhattacharyya N, Shapiro NL. Associations between socioeconomic status and race with complications after tonsillectomy in children. Otolaryngol Head Neck Surg. 2014;151(6):1055-60

3. Duval M, Wilkes J, Korgenski K, Srivastava R, Meier J Causes, costs and risks factors for unplanned return visits after adenoyonsillectomy in children, Int. J. Pediatr. Otorhinolaryngol. 2015;79(10):1640-1646.

4. Mueller J, Boeger D, Buentzel J, et al., Population based analysis of tonsil surgery and postoperative haemorrhage. Eur. Arch. Otorhinolaryngol. 2015;272(12):3769-77.

5. Schrock A, Send T, Heukamp L, Gerstner AO, Bootz F Jakob M. The role of histology and other risk factors for post-tonsillectomy hemorrhage, Arch.Otorhinolaryngol. 2009;266(12):1983-7.

6. Spektor Z, Kay DJ, Mandell DL. Prospective comperative study of pulsed-electron avalanche knife (PEAK) and bipolar radiofrequency ablation (coblation) pediatric tonsillectomy and adenoidectomy. Am J Otolaryngol. 2016;37(6):528-533

7. Ozkiris M, Kapusuz Z, Saydam L. Comparison of three techniques in adult tonsillectomy. Eur Arch Otorhinolaryngol. 2013;270(3):1143-1147.

8. Lane JC, Valenti JD, Chiado L, Haupert M. Postoperative tonsillectomy bleeding complications in children: A comparison of three surgical tecniques. International Journal of Pediatric Otorhinolaryngol. 2016;88(11):184-8

9. Windfuhr JP, Chen YS, Remmert S. Hemorrhage following tonsillectomy and adenoidectomy in 15218 patients. Otolaryngol Head Neck Surg. 2005;132(2):281-6.

10. Perkins JN, Liang C, Gao D, Shults I, Freidman NR. Risk of post-tonsillectomy hemorrhage by clinical diagnosis. Laryngoscope 2012;122(10):2311-5.
11. Kim MK, Lee JN, Kim MG, Ha SY, Lee JS, Yeo SG. Analysis of prognostic factors for postoperative bleeding after tonsillectomy. Eur Arch Otorhinolaryngol. 2012;269(3):977-81

12. Tomkinson A, Harrison W, Owens D, Harris S, McClure $\mathrm{V}$, Temple M. Risk factors for postoperative hemorrhage following tonsillectomy. Laryngoscope. 2012;269(3):97781 .

13. Ali RB, Smyth D, Kane R, Donnerlly M. Posttonsillectomy bleeding: a regional hospital experience. 2008;177(4):297-301.

14. Tomkinson A, De Martin S, Gilchrist CR, Temple M. Instrumentation and patients characteristics that influence postoperative hemorrhage rates following tonsil and adenoid surgery. Clin Otolaryngol 20005;30(4):338-46.

15. Arnoldner C, Grasl M, Thurnher D., et al Surgical revision of hemorrhage in 8388 patients after cold-steel adenotonsillectomies. Wien Klin Wochenschr. 2008;120(11-12):336-42.

16. Blakley BW. Post-tonsillectomy bleeding: how much is too much? Otolaryngol Head Neck Surg. 2009;140(3):288-90.

17. Blanchford H, Lowe D. Cold versus hot tonsillectomy: state of the art and recommendations. ORL J Otorhinolaryngol Relat Spec 2013;75(3):136-41.

18. Chowdhury K, Tewfik TL, Schloss MD. Posttonsillectomy and adenoidectomy hemorrhage. J Otolaryngol. 1988;17(1):46-9.

19. Windfuhr JP, Verspohl BC, Chen YS, Dahm JD, Werner JA. Post-tonsillectomy hemorrhage - some facts will never change. Eur Arch Otorhinolaryngol. 2015;272(5):1211-8

20. Pinder DK, Wilson H, Hilton MP. Dissection versus diathermy for tonsillectomy. Cochrane Database Syst Rev. 2011;16(3):CD002211

21. Http://Www.Rcseng.Ac.Uk/Surgeons/Research/SurgicalRe search/Docs/National\%20prospective $\% 20$ tonsillectomy $\% 2$ 0audit\%20final\%20report\%202005.Pdf/View (2005) National Prospective Tonsillectomy Audit Final Report 2005 .

22. Söderman ACH, Ericsson E, Hemlin $\mathrm{C}$ et al., Reduced risk of primary postoperative hemorrhage after tonsil surgery in Sweden: results from the National Tonsil Surgery Register in Sweden covering more than 10 years and 54,696 operations. Laryngoscope 2011; 121(11):2322-2326.

23. Liu JH, Anderson KE, Willging JP et al., Post tonsillectomy hemorrhage: what is it and what should be recorded? Arch Otolaryngol Head Neck Surg. 2001;127(10):1271-5

24. Rakover Y, Almog R, Rosen G. The risk of postoperative haemorrhage in tonsillectomy as an outpatient procedure in children. Int J Pediatr Otorhinolaryngol. 1997;41(1):29-36.

25. Tami TA, Parker GS, Taylor RE. Post-tonsillectomy bleeding: an evaluation of risk factors. Laryngoscope. 1987;97(11):1307-11.

26. Sarny SA. Multicenter prospective study on all patients undergoing tonsillectomy, tonsillotomy or adenoidectomy in Austria in 2009 and 2010. 2011 Doctoral thesis. 
27. Thottam PJ, Christenson JR, Cohen DS, Metz CM, Saraiya SS, Haupert MS. The utility of common surgical instruments for pediatric adenotonsillectomy. Laryngoscope. 2015;125(2):475-9

28. Alexander RJ, Kukreja R, Ford GR. Secondary posttonsillectomy hemorrhage and informed consent. J Laryngol Otol. 2004;118(12):937-40.

29. Attner P, Haraldsson PO, Hemlin C, Hessen Soderman AC. A 4 year consecutive study of post-tonsillectomy haemorrhage. ORL J Otorhinolaryngol Relat Spec. 2009;71(5):273-8.
30. Windfuhr J, Ulbrich T. Post-tonsillectomy hemorrhage: results of a 3-month follow-up. Ear Nose Throat J. 2001;80(11):790, 795-8.

31. Ikoma R, Sakane S, Niwa K, Kanetaka S, Kawano T, Oridate N. Risk factors for post-tonsillectomy hemorrhage. Auris Nasus Larynx. 2014;41(4):376-9.

Copyright (C) 2016 The Author(s); This is an open-access article distributed under the terms of the Creative Commons Attribution License (http://creativecommons.org/licenses/by/4.0), which permits unrestricted use, distribution, and reproduction in any medium, provided the original work is properly cited. All Rights reserved by international journal of Medical Science and Discovery. 